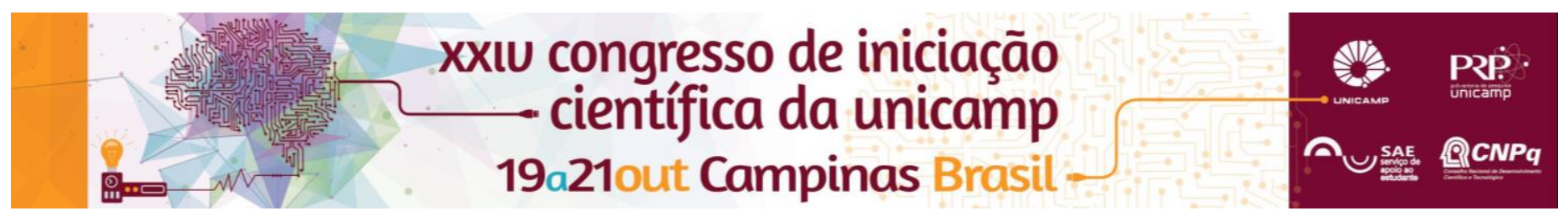

\title{
Influência do polimorfismo TP53 Arg72Pro no risco e prognóstico do carcinoma de células escamosas de laringe
}

\author{
Letícia K. Murazawa*, Bruno L. França, Gustavo J. Lourenço, Carlos T. Chone, Carmen S. P. Lima.
}

\section{Resumo}

O gene TP53 é um gene supressor tumoral, sabidamente polimórfico, cujo polimorfismo Arg72Pro é caracterizado pelos aminoácidos arginina (Arg) e prolina (Pro) nas respectivas proteínas, sendo que a proteína codificada pelo alelo Pro é menos eficiente em induzir a apoptose. Ainda é incerta sua influência no risco e prognóstico do carcinoma de células escamosas de laringe (CCEL). A análise sobre risco em nosso laboratório não indicou relação do polimorfismo com o CCEL, porém é possível sua relação com o prognóstico destes pacientes, constituindo o objetivo do presente estudo. Os dados sobre a terapêutica e sobrevida dos 203 pacientes com CCEL atendidos nos ambulatórios de Oncologia Clínica e de Otorrinolaringologia do Hospital de Clínicas da UNICAMP estão em fase final de levantamento. Serão avaliados os impactos de aspectos clínicos, biológicos do tumor e genótipos do polimorfismo TP53 Arg72 na sobrevida global (SG) dos pacientes com CCEL. As estimativas de SG serão calculadas por meio das curva de Kaplan-Meier e as diferenças entre curvas pelo teste do log-rank. Os significados dessas diferenças serão também avaliados em análises univariada e multivariada de Cox. O nível de significância estatística adotado para os testes estatísticos será de 5\% $(P<0,05)$.

\section{Palavras-chave:}

Carcinoma de laringe, Gene P53, Prognóstico

\section{Introdução}

O carcinoma de células escamosas de laringe (CCEL) apresenta altas taxas de incidência, de mortalidade e sequelas terapêuticas ${ }^{1}$.

Anormalidades em genes envolvidos com o reparo de lesões de DNA e de indução de apoptose de células cujo DNA não pode ser reparado podem estar associadas à ocorrência do CCEL². O polimorfismo TP53 Arg72Pro foi associado com variável habilidade herdada para a indução de apoptose: o alelo Pro codifica proteína menos eficaz do que o alelo Arg no processo ${ }^{3}$. O papel deste polimorfismo no risco do CCEL, nas manifestações clínicas e biológicas do tumor, bem como em seu prognóstico é incerto.

Resultados obtidos inicialmente em nosso laboratório sobre a análise do risco indicaram que os diferentes genótipos do polimorfismo TP53 Arg72Pro não alteram o risco de ocorrência do CCEL na população geral. Entretanto, o genótipo ArgPro+ProPro pode estar associado à ocorrência do tumor em indivíduos não brancos (64,6\% versus 40,6\%, $P=0,005 ; P A=83,9 \%)$. Observou-se então, a necessidade da análise da relação entre o polimorfismo e sobrevida dos pacientes, ainda não descritos na literatura. Assim, este constituiu o objetivo do presente estudo.

\section{Resultados e Discussão}

Os aspectos clínicos, biológicos do tumor, dados de terapêutica, bem como de sobrevida global (SG) dos pacientes foram obtidos dos prontuários médicos.

A SG considerou o período entre o diagnóstico e a morte por qualquer causa ou perda de seguimento.

Os genótipos do polimorfismo TP53 Arg72Pro foram identificados no Laboratório de Genética do Câncer (LAGECA).
A análise estatística da SG será calculada por meio da curva de probabilidade estimada de Kaplan-Meier e a diferença entre curvas pelo teste do log-rank. A significância dessas diferenças será também avaliada em análise univariada de Cox. Em um segundo tempo, todas as variáveis com $P \leq 0,10$ serão incluídas na análise multivariada de Cox. O nível de significância adotado para os testes estatísticos será de $5 \%(P<0,05)$. Os dados obtidos ainda estão em análise e é por isso que não se encontram aqui descritos. Acreditamos que estes resultados poderão contribuir para identificar grupos de pacientes com prognósticos distintos, que possam ser selecionados para receber terapêuticas diferenciadas em estudo futuro, no moderno conceito de tratamento personalizado do câncer.

\section{Conclusões}

A análise dos resultados de sobrevida ainda se encontra em andamento, não sendo possível chegar a uma conclusão sobre a relação entre o polimorfismo e o prognóstico do CCEL.

\section{Agradecimentos}

Este trabalho foi realizado com o apoio do Conselho Nacional de Desenvolvimento Científico e Tecnológico (CNPq). Agradecimentos ao grupo de pesquisadores do Laboratório de Genética do Câncer (LAGECA), que contribuíram com a realização do estudo.

${ }^{1}$ INSTITUTO NACIONAL DO CANCER. Estimativasda incidênciade câncerno Brasil. http://www.inca.gov.br/estimativa/2016.

${ }^{2}$ HA, P.K.; CALIFANO, J.A. The molecular biology of laryngeal cancer. OtolaryngolClinics of North America, 35:993-1012, 2002.

${ }^{3}$ DUMONT P, LEU JI, DELLA PIETRA AC, et al. The codon 72 polymorphic variants of p53 have markedly different apoptotic potential. Nature Genetics, 33:357-65, 2003. 